\title{
Using Prodigy and Other Online Services in the Political Science Classroom
}

\author{
David Alexander Bowers, Jr., University of Southern Mississippi
}

Commercial online computer services provide a wealth of features that can be helpful in teaching political science. The four most prominent services are Prodigy, America Online, CompuServe, and Delphi. ${ }^{1}$ All feature a variety of materials including news headlines, recent political news, a database on Congress, recent speeches, and an encyclopedia. A host of other features, while not of immediate relevance to political science classes, can be useful-everything from information on computers to keeping track of airfares.

Prodigy, America Online, and Delphi are best suited to undergraduate teaching, particularly introductory courses. These three do not, though, offer the depth of analysis or the breadth of sources to be suitable for advanced researchers. Researchers online would be better served by CompuServe, which through IQuest and other features offers access to over 850 databases. However, having all this information at one's fingertips is not cheap. IQuest costs $\$ 9.00$ a search, $\$ 3.00$ for an abstract, and up to $\$ 75.00$ an hour to search some databases.

Prodigy, America Online, and Delphi lack access to these advanced features, but their structure and pricing make it possible for students to have their own accounts and to use the service without fear of running up a large bill. The professor must weigh the limitations of these services against the possibility that some students may incur large charges using certain features of CompuServe.

These services constitute the first lane being laid down on the electronic superhighway. A major hightechnology project of the Clinton administration has been to push for a nationwide electronic superhighway to propel the American economy into the twenty-first century (Prodigy 7/8/93). If we familiarize and assist our students in making use of the electronic highway, we will have made a significant contribution to their education.

Online services are moving to supplant newspapers and other traditional forms of physical communication. In fact, Prodigy has formed a joint venture with the Cox newspaper chain to circulate several newspapers electronically. According to reports, "The Cox deal with Prodigy will include community bulletin boards, databases of material originally published in print, expanded analyses and background on news articles, restaurant reviews and directories of community services"' (Prodigy 7/8/93).

America Online has also entered into partnerships with several newspapers including the Chicago Tribune and the San Jose Mercury News. In addition, America Online allows users to read Time magazine online and reply to articles. CompuServe has similar features using U.S. News and World Report.

It seems likely that students in the future will be reading newspapers and magazines on the screens of their portable computers. One reason is that newsprint and ink are neither very efficient, nor friendly to the environment. Another factor favoring the computer is that readers can choose only those parts of the news in which they are interested. For an extra fee, CompuServe allows users to have the computer scan wire services using keywords, allowing articles to be filed electronically. Readers are less likely, therefore, to miss an article relevant to their area of interest.

Even in the era of Super Nintendo and home computers, many students feel a great deal of anxiety about computers and technology. For instance, a recent poll taken by Dell computers "found that $27 \%$ of the adults surveyed had never used a computer; $55 \%$ had never bought one; $32 \%$ of adults 'feel intimidated using computers', and $25 \%$ 'miss the days when we just had typewriters", (Magid 1993). Political science professors can do much to guide the future educational paths of students through the use of online communication.

I used Prodigy in my Introduction to American Government class; 1 therefore, I am most familiar with how students interact with Prodigy. Since the other commercial online services offer comparable features, I strongly believe they will perform in a similar manner.

\section{Advantages of Online Services}

\section{Ease of Use}

All the online services can be used on a wide variety of computers. The services discussed here have versions for both PC computers and Macintosh computers. Generally, the specially designed software is easy to install. One of my students who had a Wang laptop had difficulty installing the Prodigy software, but was able to quickly complete the task once she called the 800 number provided for assistance.

The online services surveyed in this article are designed for a mass user base and therefore are easy to use. These services feature an extensive menu system. Some students who had no background in the use of computers found Prodigy's menu system difficult to use. One student wrote in her journal, "My first encounter with the Prodigy assignment was a very interesting one. I managed to clear the screen some kind of way and had a ten minute or so delay on progress in my work." On the other hand, another student wrote, "for someone like me, who is completely computer illiterate, Prodigy is simple and easy to use."

Even though the online service software is more flexible than many 
computer applications, one has to be precise in selecting commands. For example, in one of my assignments on Prodigy, I typed "close-up bb" with quotation marks. Many of the students duplicated this command with the quotation marks, and the computer did not take them to the close-up bulletin board.

\section{Currency of Data, Information, and Opinion}

One of the great virtues of online services is that information is current. If there are developments in a story or changes in interpretation of events, they will be reflected much more quickly than in print sources. This alone can stimulate student interest. For instance, on election day in 1992, results were updated every 30 minutes.

All the services offer forums for discussing political topics. Students can read electronic mail and post mail on these forums. These electronic discussion groups go by different names on the online services. On CompuServe the discussion group is the "political debate forum"; on America Online it is the "Bull Moose Tavern"; on Delphi it is "Views on the News"; and on Prodigy it is the "close-up bulletin board."' A professor who provides students with a solid grounding in the subject of political ideology can use these discussion groups to show that political ideology is relevant to policy disputes occurring in the world today.

For example, one student found the whole discussion of political ideology rather dull and not very relevant. However, using the electronic discussion group stimulated his interest when he read about a proposed California law that would take away the driver's license of anyone caught possessing, or under the influence of, marijuana.

\section{Depth on National and International Issues}

All the online services offer more depth on national and international issues than offered in many local newspapers, particularly when these papers are in the smaller media markets. For instance, Prodigy has offered much more complete coverage of the ongoing events in the former Yugoslavia than most local newspapers.

\section{One of the great virtues of online services is that information is current. If there are developments in a story or changes in interpretation of events, they will be reflected much more quickly than in print sources.}

In doing one assignment, many students were able to "travel" electronically to read opinions on public policy which they found radically different from what they hear in the small towns of southern Mississippi. Online services' ability to allow students to interact with people throughout the country provides a useful teaching tool, particularly concerning topics such as ideology, Congress, the presidency, the Supreme Court, and a multitude of other political science topics.

\section{Ability to Link and Interrelate Topics}

Online services, especially Prodigy, have the ability to link one article to other articles of related content. Students can read about President Clinton's bombing of Iraq and the transcript of his speech to the American people, then go to the online encyclopedia to read articles about Clinton, Iraq, and Saddam Hussein. Admittedly, students should be familiar with all these topics, but many students lack the necessary background, particularly in lower level courses.

\section{Enhanced Ability to Communicate}

By using electronic mail, students can communicate with each other and with the professor. This might be handy for students who have questions about an assignment, or for those who need to exchange electronic mail as part of an assignment or simulation. In the class I taught, students did not take advantage of this. In general, as at many large state universities, there are barriers to communication between students and faculty. Electronic mail was not used as a means to overcome these barriers. Many of the students worked in the Political Science Computer Lab across from my office. If they had questions, they merely asked me in person. The few students who used computers away from the lab did not take advantage of electronic mail. Perhaps, if I had spoken more about electronic mail in class and encouraged its use, more students would have taken advantage of this feature.

Individuals using online services have the ability to communicate with $\mathbf{3 0}$ million others on Internet. Internet is a U.S.-government supported consortium of government, academic, and corporate computer networks worldwide. The online service that is best integrated into Internet is Delphi. Delphi can be reached through TELNET, a feature of Internet, which allows the user to access Delphi without any connection charge. This is especially useful if your campus has TELNET, when none of the online services have local numbers. Delphi provides a gateway to use the features of the Internet. At this writing, most observers agree that Delphi has the best connections to Internet for those who lack access via an academic computer, or other gateway, and who must depend on a commercial service. Generally, for most academic professionals, the local computer network is the cheapest way to access Internet.

\section{Disadvantages of Online Services}

\section{Cost}

There are four elements in determining the cost of these online services. The first charge is for connecting into the system. If you live 


\begin{tabular}{|c|c|c|c|c|c|c|c|c|c|c|}
\hline $\begin{array}{l}\text { TABLE } 1 \\
\text { Features of } 0\end{array}$ & Services & & & & & & & & & \\
\hline Service & Phone Info. & Price & Free Basic & $\begin{array}{c}\text { Special } \\
\text { Software }\end{array}$ & $\begin{array}{c}\text { Color/ } \\
\text { Graphics }\end{array}$ & $\begin{array}{c}\text { P.S. } \\
\text { Forums }\end{array}$ & News & E-Mail & $\begin{array}{c}\text { Internet } \\
\text { Mail } \\
\text { Link } \\
\end{array}$ & $\begin{array}{c}\text { Open } \\
\text { Via } \\
\text { Internet }\end{array}$ \\
\hline Prodigy & (800) 776-3449 & $\$ 14.95$ & No limit & Yes & Yes & Yes & $\begin{array}{l}\text { Own; AP; } \\
\text { Reuters }\end{array}$ & Yes & Yes & No \\
\hline America Online & (800) 827-6364 & $\$ 9.95$ & 5 hours & Yes & Yes & Yes & $\begin{array}{l}\text { UPI; USA } \\
\text { Today }\end{array}$ & Yes & Yes & No \\
\hline CompuServe & (800) 848-8990 & $\$ 8.95$ & No limit & Yes & Yes & Yes & $\begin{array}{l}\text { AP; others } \\
\text { for more } \$\end{array}$ & Yes & Yes & No \\
\hline Delphi & (800) 695-4005 & $\$ 10$ & 4 hours & No & No & Yes & $\begin{array}{l}\text { Reuters; } \\
\text { UPI }\end{array}$ & Yes & Yes & Yes \\
\hline
\end{tabular}

in a small town and must dial a number in a large city to connect to the service, the charges can be high. Some of the services can be reached through various networks such as British Telecom's TYMNET or Sprint's Sprintnet, but often there is an additional fee, which can be substantial, particularly during business hours.

The second cost is a basic fee, which I have listed in Table 1. Prodigy and CompuServe allow unlimited use of their basic features for the basic fees. Additional charges apply for America Online after five hours and for Delphi after four hours.

The third element has to do with the nonbasic services, which have additional hourly charges, and sometimes additional supplements. The speed of one's computer modem may also influence these nonbasic charges.

The final element of the cost is the number of users who can use the same account. Prodigy allows up to five family members or in this case, students, to be placed on the same master account. Five students can be put under a professor's single membership at a basic rate. ${ }^{2}$ America Online has a similar deal allowing four additional members under the same account. Therefore, the professor becomes the primary member.

The primary member has the ability to limit student access to expensive bulletin boards and other features, can monitor student use of the account, and is also the only member who can assign students to some accounts and cancel accounts. The other two online services do not seem to encourage multiple users on the same account and do not offer similar features. Pricing and other policies vary among the online data services, and, unfortunately for the purposes of comparison, are always changing. The reader should contact the numbers listed in Table 1 for additional pricing information.

\section{Limited Student Access to Personal Computers and Modems}

In order to take maximum advantage of the system it would be desirable for students to own their own computers, preferably with hard drives and modems, because graphically oriented online services run very slowly on computers with only two disk drives. At the time of my Prodigy study, few students at the University of Southern Mississippi owned their own computers; they used computers in the Political Science Computer Lab. The professor was available for the first assignment, and students obtained keys from the secretary for the second assignment.

The major expense and difficulty with using the PC lab was that each computer needed its own phone line. For my class of 25 , we were able to get by with two phone lines. Despite having only two computers available, there were not long waits for the students. When more students have their own computers they can use the phone lines at home or in the dormitory, and not be dependent on limited equipment in a lab.

\section{Technical Problems}

All the online services suffer from a few technical problems. CompuServe's CIM software occasionally froze up and refused to take any more commands from either the keyboard or mouse. Prodigy sometimes has difficulty printing items from the screen, particularly graphics. The students in my study had trouble printing the bar graphs that summarized the results of the Prodigy poll. In addition, Prodigy can be much slower than the other online services because Prodigy features a number of graphics and it takes time for the computer to properly format them. The service tries to short cut this process somewhat by storing a number of the graphics on the user's own hard drive. Prodigy has also tried to address this problem by adding support for 9600 bps modems in many locations and does not charge extra for this service.

One way to short cut the slow speed of telephone lines is to use cable. Prodigy, as well as the other online services, has plans to be part of the interactive television revolution. Because cable television transmission lines can handle more information than conventional telephone lines, the hope is that online services can be made quicker and time spent waiting for graphics to appear will be shortened.

Users of America Online have suffered delays in signing onto the service. America Online has grown $145 \%$ in the past year and has suffered growing pains resulting in its president, Steve Case, writing an online letter to members apologizing for the delays (Leyden 1994). 
This service has been forced to ration use between certain hours. Professors should make students aware of capacity issues for online services.

\section{Limitations of Electronic Mail}

I considered the possibility of students submitting their papers via electronic mail. However, for Prodigy, as well as the other online services, electronic mail lacks some features of a fully functioning word-processing system, such as "spell check." There is also a fairly short limitation on document length. From a practical point of view, and since many of the students were using the lab and not their own computers, it did not make sense to force them all into the lab the day before the paper was due.

Some of the services have problems connecting with the Internet system. Prodigy, America Online, and CompuServe can only send and receive electronic mail from Internet. In addition, Prodigy charges fees per message which can be quite high if the user receives a great deal of electronic mail from Internet.

\section{Increased Time and Efiort for the Instructor}

Any instructor who uses online services will be investing considerable time and effort. Unless the instructor has each student buy the online service at the university book store or other retail outlet, the instructor will be responsible for handing out the accounts. In most situations money will have to be collected directly from students and refunds given to those students who drop the course. A possible solution is an additional fee that is collected as part of registration.

The instructor must create assignments that make use of the online services' unique features, while illustrating meaningful points about political science. For example, a first assignment might examine ideology in American politics using the discussion groups where members write on current political is- sues. A second could require students to take an online poll, and to write a paper examining the usefulness of learning public opinion by convenience sample and the prospects for democracy if citizens could vote on every issue using their computers and modems. A third assignment could ask the students to analyze a presidential speech or transcript of a news conference.

The instructor should be available to assist the students with the computers and signing onto the service, or have trained graduate or undergraduate students do this.

\section{Temporary Availability of Materials}

Many articles, notes, etc., are deleted from the services after several weeks, while some materials are retained for long periods. Students must print a copy of materials examined for the instructor to check the content of the assignment.

One student failed to print electronic mail from the online discussion group as he had been instructed. When asked to produce the electronic mail, the student was unable to retrieve it because it had been removed from the discussion group. Unlike a collection of newspapers in the library, which will probably be put on microfilm, there is no easily accessible permanent record of what appears on online services.

\section{Excessive Commercialism}

Online services are private businesses that want to make a profit. They try to get the computer user to spend money in a variety of ways. Almost all encourage the user to buy a book describing their service in great detail. All prominently feature online shopping.

Prodigy's relatively low cost comes with a drawback-advertising. Prodigy does not allow the user to make full use of their monitor, since about $20 \%$ of the screen is devoted to advertising. Besides being annoying, the phone line to the modem is sometimes tied up with advertising material. Though the use of materials containing advertising for primary and secondary schools has caused great controversy, such as the Whitten Corporation's Channel One, I would argue that Prodigy in this regard is really not different from having the students use the New York Times, which also contains advertising. However, none of the other online services uses advertising in this way, indicating that this sort of medium can be operated without such intrusive interruptions.

\section{Conclusion}

Part of the traditional role of the teacher has been to introduce students to different ways to retrieve and use information. As the world of information moves from books in the library to the files on the computer, we have a duty to teach our students to be able to operate in this new environment. We can provide our students with experiences that allow them to encounter the exhilaration of this new world, while understanding the pitfalls of the new information technology.

One pitfall, as demonstrated by CompuServe, and to a lesser extent by all the online services, is that while libraries have been traditionally free to all students, research use of commercial databases can quickly become expensive. There is the threat that some will not be able to afford such services. If the problems of differential access can be solved, commercial online services can provide an excellent introduction to the information superhighway for introductory political science students.

\section{Notes}

1. Prodigy, America Online, CompuServe, and Delphi are registered trademarks. The trademark symbol is not used throughout this article as a convenience.

2. Prodigy sent me several free kits that included the software and one free month of service. I had to contact the sales office in my region for these kits. In addition, I took advantage of free offers made to the public to use the other online services. Additional funds were provided by the University of Southern Mississippi Alumni Fund for Political Science. This paper represents neither 
the views of the various online services nor the USM Alumni Fund.

\section{References \\ Leyden, Peter. 1994. "Life in the Fast Lane?: Not Yet - Heavy Use of Informa- tion Superhighway Has Created Traffic Jams." Minneapolis Star Tribune, 9 Feb- ruary 1994, Sec D. \\ Magid, Larry. 1993. "Adult Proof Caps." Prodigy. \\ Markoff, John. 1989. "Betting on a Different Videotext Idea." New York Times, 12 July 1989 , Sec. D.}

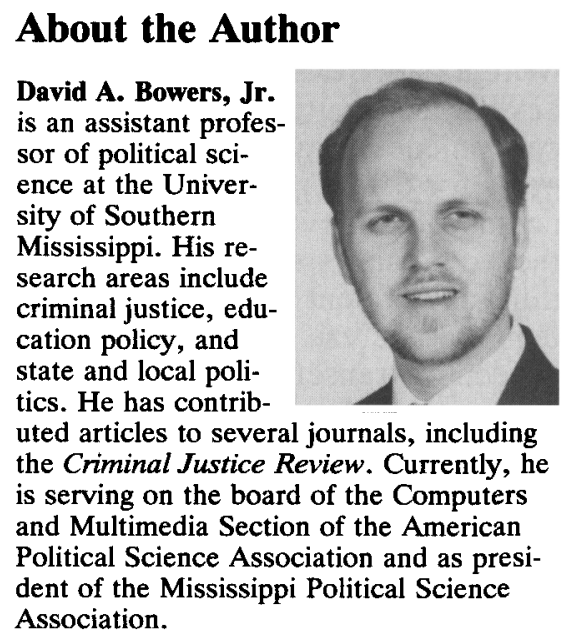

\title{
Revitalizing Undergraduate Programs Through Intercollegiate Mock Trial Competition
}

\author{
John R. Vile and Thomas R. Van Dervort, Middle Tennessee State University
}

\begin{abstract}
Although the movement currently appears more prominent at the high school than the college level, recent years have witnessed an upsurge in law-related education programs. Studies have shown that such programs have been successful not only in educating students about the role of law and other governmental institutions in society but also in reducing criminal activity (Van Dervort 1994, 32).

Because of the proliferation of materials related to law-related education, educators must choose those most suitable to their own objectives and programs. As political scientists who teach law-related courses to undergraduates at a state university, we have found mock trial competition to be a highly effective way of giving our students a first-hand look at how courts operate, leading them to a better understanding of the legal system, and interesting and involving them in our prelaw program.
\end{abstract}

\section{History and Description of Mock Trial Competition}

This year, 1994, marked the tenth year of intercollegiate mock trial competition with over 115 colleges and universities and over 200 teams participating in this activity; this marked a jump from eight schools and twelve teams who had participated in the first national tournament in 1985 (American Mock Trial Association, 1994, 6). The mock trial program received a major boost early in its history in 1985 when the Conference of State Chief Justices meeting in Williamsburg, Virginia, endorsed mock trial competition as a means of promoting greater understanding of the legal system. Initially, the national collegiate tournament was sponsored by the Drake University Law School in Des Moines, Iowa. Richard Calkins, then dean, was influential in establishing mock trial competition, and he has subsequently served as the guiding light of the American Mock Trial Association.

AMTA has now become an independent corporation with an expanding board of directors made up of representatives from undergraduate institutions throughout the country. In addition to the national tournament, AMTA sponsored a variety of invitational tournaments and 11 regional mock trial competi- tions during the 1993-94 school year. These, in turn, qualified students to participate in one of three flights of national competition, two held in Des Moines, Iowa, and the third (primarily for new schools) held at the University of Wisconsin at Milwaukee. The activity is also growing at the high school level, providing colleges and universities with established mock trial programs an effective recruiting tool that is especially appealing to good students.

As the name of the activity suggests, mock trial competition focuses on student enactments of trials. Unlike the corresponding moot court competition that is more common in law schools, undergraduate mock trials focus on state trial courts rather than federal appellate courts. This emphasis provides a balance for students who have taken constitutional law and other undergraduate classes that almost always focus on federal rather than state courts (Galie 1993), and that almost always examine appellate court decisions, thus perpetuating what Jerome Frank once called the "Upper Court Myth" (Frank 1969, 222).

Each year, the American Mock 